\title{
SUPPORTIVE CARE NEEDS AND THEIR ASSOCIATIONS WITH PSYCHOLOGICAL WELL-BEING, ILLNESS BELIEFS AND QUALITY OF LIFE AMONG CANCER PATIENTS IN INDIA
}

\section{INTRODUCTION}

Needs assessment provides a quick and clear measure of patients' support preferences, assist in identifying gaps in present services, and improve resource distribution (Zigmond \& Snaith, 1983).

Psychological and health information needs are frequently identified as the most commonly reported unmet need by cancer patients (e.g., Razavi et al., 1990; Chie et al., 2004;

Broadbent et al., 2006).

\section{AIMS}

To examine patients' supportive care needs and associations between these and psychological distress, symptom experience, illness perceptions and quality of life (QoL) among cancer patients in India.
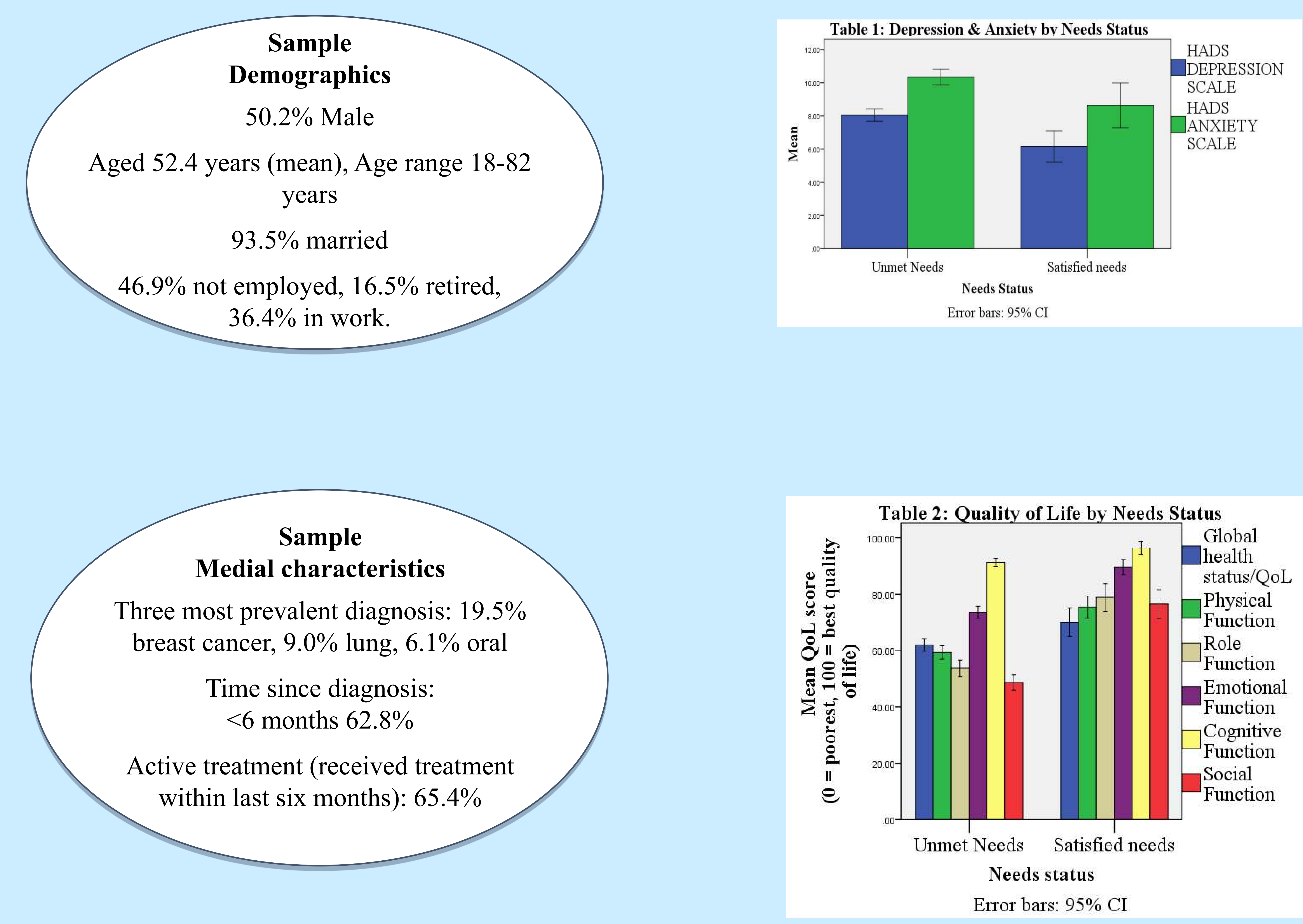

RESULTS

The three most prevalent unmet needs for those on active treatments were:

Five hundred and twenty-two patients were recruited

from cancer hospitals in Hyderabad, India.

Patients with a terminal illness were excluded.

Scales included:

1. Supportive Care Needs Survey SF 34 (SNCS SF 34; Boyes, Girgis, \& Lecathelinais, 2009)

2. Hospital Anxiety and Depression Scale (HADS; Zigmond \& Snaith, 1983)

3. Condensed Memorial Symptom Assessment Scale (CMSAS; Chang et al. 2004) Brief illness perception questionnaire (BIPQ; Broadbent et al. 2005)

4. European Organization for Research and Treatment of Cancer Quality of Life Questionnaire (EORTC QLQ-C30; Aronson et al. 1993)

\section{CONCLUSIONS}

Patients with unmet needs had:

$\checkmark$ higher levels of psychological distress

$\checkmark$ more physical and psychological symptoms

$\checkmark$ negative illness beliefs

$\checkmark$ lower QoL

\section{IMPLICATIONS}

Patients may benefit from psycho-oncology services.

Further, future research can examine the impact of these psycho-oncological services on patients' well-being. 